\title{
SLA: Concept of Context in Community
}

\author{
Nima Shakouri Masouleh \\ Roudbar Branch, Islamic Azad University, Iran \\ Email: Nima.Shakouri2011@Gmail.com \\ Razieh Bahraminezhad Jooneghani \\ Universiti Sains Malaysia (USM), Malaysia \\ Email: Razieh.bj@gmail.com
}

\begin{abstract}
Hymes (1972), forty years ago, maintained that knowing what goes on outside the school setting is necessary to understanding what goes on inside. He noted further that "the key to understanding language in context is to start not with language but with context. As Wendt (2003) concludes context must be regarded as causes for construction of meaningful realities and for checking their viability. Policymakers, practitioners and researchers have long understood that well-established context drives learners towards success, whether this success is defined as opening a simple talk with a neighbor or learning a language. Programs and policies, however, have focused almost exclusively on improving teaching and learning quality through investments in human capital rather than in exercising context as an appropriate success causer. The present study is an attempt to persuade policy makers to reconsider their ideology.
\end{abstract}

Index Terms - context, socialization, social learning theory

\section{INTRODUCTION}

Recently, the importance of learning context has stirred debate within SLA circles. The field of second language acquisition has long been dominated by cognitive-oriented theories. Some sscholars contended that it is important to provide an understanding of the acquisition process in psycholinguistic terms relatively independent of external factors. But there was a gradual shift toward a concern with the social aspects of learning, as well. Researchers such as Firth and Wagner (1997) contend that it is the language use that forms cognition and the interaction of social activity and psycholinguistic elements as the best predictive model of SLA. One of the strongest and most immediate reactions to Firth and Wagner (1997) came from Long (1997). He argues social context has no impact on the learner's cognitive processes, and therefore, that issues of social context fall outside the scope of SLA theory. Conversely, Firth and Wagner (1997) criticized the field of SLA for its exaggerating cognitive orientation towards language development. They invoke Vygotsky in asserting that cognitive structures are influenced and, indeed, developed through engagement in social activity. They maintain that language acquisition "is built on language use" (p. 806) and that it is a process that takes place "in the micro moments of social interaction" (Firth \& Wagner, 2007, p. 807). Without negating the importance of cognitive dimensions, the importance of social context in second language acquisition is reviewed.

\section{LITERATURE REVIEW}

\section{A. Cognition is Built on Language Use}

Language is the product of interaction; essentially, we are inheritably destined to interact with others to gratify our needs. As Firth and Wagner (1997) noted "language is acquired and learned through social interaction and should be studied in interactive encounters" (p. 287). To better appreciate the concept of the socio-cultural nature of language development in a social context, it is worth a moment to briefly review Vygotsky's (1979) sociocultural theory, Bakhtin's (1981) dialogical perspectives, and critical theory. They undeniably have tremendous effects on the flourishing of social-oriented perspectives of language development. Two basic tenets of Vygotskian sociocultural theory are activity theory which reflects the fundamental idea that motives for learning in a particular setting are intertwined with socially and institutionally defined beliefs; and mediation which proposes that human mental activity is mediated by tools and signs, the foremost tool being language (Sullivan, 2000, p. 115) To Vygotsky (1979) (as cited in Zungler \& Miller, 2006), language development results from transforming innate capacities rather than by unfolding them. And the transformation of innate capacities happens once they intertwine with sociocultural constructed means, which are either physical or symbolic. When these means become available for individuals to begin interaction in socially meaningful activities they gain control over their mental activity.

Bakhtin's dialogical perspective emphasizes the sociality of intellectual processes. To Bakhtin, language lies on the border between oneself and the other. What Bakhtin calls as dialogism connotes mutual participation of speakers and hearers in the construction of utterances and the connectedness of all utterances to past and future expressions. Bakhtin 
viewed our use of language as an appropriation of words that at one time existed in other people's mouths before we make them our own. As Hall (2002) claims, in such a view, an utterance can be understood fully by considering its history of use by other people, in other places for other reasons (cited in Zungler \& Miller, 2006).

And the utterance that we produce, from a critical theory perspective, reveals our stance towards the interlocutors, signaling our social positioning within the local interaction and in response to larger sociopolitical forces. In this case, the role of social power can be understood in the social world. What these perspective are unanimous is that language development is the product of social activity.

\section{B. The Purpose of Social Context}

As it is put by Mitchell and Myles (2004) "the relationship between the individual learner and the social context of learning is viewed as dynamic, reflexive and constantly changing” (p..27). In fact, the social context determines the actual nature of possibilities for social intercourse and other communicative transactions. Fostering positive attitude within instructional setting depends greatly, as Spolsky (1988) states, on the duration and quality of teaching and on the social context of instruction. In contrast with individual differences' tradition that saw that relationship as being governed by a bundle of learner traits or characteristics (such as aptitude, anxiety, etc.), which were relatively fixed and slow to change, more socially oriented researchers view motivation, learner anxiety, etc., as being constantly reconstructed through ongoing second-language experience and second language interaction.

According to Spolsky (1988), social context can be expressed in terms of either macro policies (such as the determinations of the official language of a country) or micro policies (such as a family's decisions about what language(s) to speak at home). The former is concerned with the relationship between the learner and the society. An immigrant who moves to a new country and is immediately immersed in an unfamiliar culture, which may be radically different from his own, may experience various relationships with the host culture, ranging from complete rejection of the host culture to complete acceptance and internalization of host culture norms. This process of adapting to the host culture over time is frequently called acculturation. Micro policies, in contrast, were concerned with individual's personal social network, issues such as a family's decisions about what language(s) to speak at home. Such networks are classified as either exchange networks where communicative transactions result in an exchange of goods and services and there is an mutual obligation between the individuals, or as interactive networks, where communication is more likely to be unidirectional and there is no implied obligation between individuals, such as speaking with a pharmacist when picking up a prescription or listening to a sermon at church.

A simple glance at what was mentioned, it can be concluded that both local micro structures and political, social and universal macro structures are the inevitable stones of a social context. In Critical Discourse Analysis, as Van Dijk (2006) views, the macro structures are defined in terms of groups and their relationships such as dominance and inequality. In effect, macro context refers to historical, cultural, political and social structures in which a communicative event occurs, whereas micro context shows the features of the immediate situation and interaction in which a communicative event occurs. Van Dijk (2006) defines micro context based on the concept of cognition and considers it as a form of mental model of a communicative situation and calls it a context model. Context models are mental representations that control many of the features of text production and comprehension such as genre, choice of topic, and cohesion on one hand, and speech act, style, and imagery on the other. These models exist in people's long term memory; the part of memory in which people save their knowledge and view about the events they experience. In fact, there is no direct relationship between society and discourse and these models explain how discourse indicates the social and personal features in itself, and how in a certain social situation discourse could be different. In other words, devoid of these mental models, it cannot be explained and described that how social structures affect discourse and get affected in turn.

Siegel (2003) classifies the ways of analyzing social context in SLA along three parameters: Macro vs. micro, structural vs. interactional, and objective vs. subjective. Macro-analysis focuses on the society as a whole and the characteristics of the various social groups that compromise it. The micro-level analysis pays attention to the behavior of individuals in particular situations which results from broader social factors.

In the structural point of view, power, prestige, and other specific aspects of social context are considered as determined by the structure of the society and by the historical forces that shaped this structure. For example, a person's social identity is the result of the particular social group to which she or he belongs and the position of this group in society. SLA may be affected directly or indirectly by these sociostructural or sociohistorical factors. In contrast, the interactional point of view sees social context not as given, but as created in each specific situation by the interplay of several social factors. According to this view, a person has multiple social identities, and the one that emerges in a particular situation is determined not only by the person's group membership but by the social interaction. Social identities and relationships may be continuously changing and renegotiated as the interaction proceeds. The particular kind of language used both reflects and creates one's social position and identity in the interaction. It affects the interaction and, at the same time, the way the interaction proceeds affects the language that is used. According to Firth and Wagner (1997) there is a "reflexive" relationship between second language learning and use and the social context. SLA is affected by the context and the context may also be affected by it.

Finally, the objective perspective concentrates on the observable aspects of the social context, while the subjective perspective concentrates on individuals' perceptions of these aspects. For example, a person's social identity may be 
determined objectively by membership in a particular social group or by the characteristics of a particular social interaction, but subjectively by attitudes toward this and other groups or by perceptions of the social interaction. According to Siegel (2003, p. 184) while the objective perspective looks at the institutional associations of particular languages, the subjective perspective looks at symbolic associations.

Bluestone (2009, p. 149) adds another category to the relationships at macro- and micro- level, and that is relationships at the internal level which is concerned with the learner's sense of self-identity. It is concerned with the relationship of the learner with himself - i.e., how the learner perceives himself changing in relation to others in his social sphere.

\section{Languages Are Learned in Social Context}

Spolsky (1989) views language is as primarily a social mechanism since languages are learned in social context. He further indicates while language learning is individual, it takes place in society, and though social factors may not have a direct influence, they have strong and traceable indirect effects. Similarly, Van Lier (1996) argues that language use and language learning are part of the word in which learners live and therefore any activities undertaken in the classroom must be understood in context.

Accordingly, Spolsky (1989, p. 26) argues that the social context influences second language learning in two indirect but important ways. Firstly, it plays a vital role in the development of the learner's attitude towards the target language, its speakers, and the language learning situation, which includes the learner's expectations and perceptions of the learning and its probable outcomes. These expectations and perceptions lead to the development of the learner's attitudes and motivation. In this respect, Wilkins (1974, pp. 47-48) indicates that in communities where the target language is observed with "indifference or even hostility", social and cultural attitudes have a considerable influence on individual learners' attitudes and motivation. Generally historical and political reasons are the cause for the given language to be regarded favorably with great hostility. Secondly, the context establishes the social condition of the language learning situation (formal and informal) and the various opportunities for language learning. Formal situations are the provision of different educational institutions in society for language learning, whereas informal situations reflect the potential opportunities in society for exposure to the target language. Studies suggest that there is high correlation between the kind of exposure to the target language and the proficiency attained.

Ellis (1994) claims, "The social context can influence the extent to which transfer occurs" (p. 317). Negative transfer, as Odlin (1989, cited in Ellis, 1994), has suggested is less likely in focused contexts, where there is concern to maintain the standardness of language, than in unfocused contexts. It is worth a moment to make a distinction between focused and unfocused contexts. The former has a very clear idea of what constitutes a language, while the latter doe not. Odlin (1989) suggested that negative transfer is less common in classroom settings than in natural settings because in the former learners constitute a focused community and as a consequence treat L1 forms as intrusive and even stigmatized (cited in Ellis, 1990, p. 317).

\section{Socialization and Social Context}

Socialization is the process by which individuals are assisted to become members of their social groups (Kesbir, Uttal \& Gardner, 2010). Maccoby (2007) defines socialization as processes whereby naïve individuals are taught the skills, behavior patterns, values, and motivations needed for competent functioning in the culture in which the child is growing up (p. 13). Socialization process can be interpreted from socio-cognitive and cross-cultural perspectives (Kesbir et al., 2010). The former deal with the immediate environmental functions as a socialization agent by activating and inhibiting knowledge structures an thereby shaping cognition and behavior, while in the latter, cross-cultural perspective, because the immediate environment factors into cognition and behaviour, socialization efforts should involve the modification of the environment for optimal effects.

Providing descriptions and explanations for linguistic development, the acquisition of syntax, for instance, is a primary much cognitivist second language acquisition research. There is naturally an attendant concern with cognition, particularly in terms of the internalization, storage, retrieval, and use of linguistic knowledge. Language socialization research, in contrast, seeks to explain learning in much broader terms, examining not only linguistic development, but also the other forms of knowledge such as culture, social knowledge, ideologies, and epistemologies, etc. (Duff \& Talmy, 2011).

Similarly, in language socialization, context including macro levels and micro levels refers to the whole set of relationships in which a phenomenon is situated (Watson-Gegeo, 1992, cited in Watson-Gegeo \& Nielsen, 2003 p. 165). Research in social cognition has shown that minimal elements of the social environment may have consequences for social interactions. The presence of some people, their ethnicity, gender, clothing, or accent may activate related knowledge, in the absence of any exchange between these social actors (Kesbir et al., 2010).

Drawing on the work of Strikant and Roberts (2004) elucidates that socialization in the social context can be investigated in terms of "indexicality and alignment" (p. 1999). The former, indexicality, that is at the heart of socialization (Ochs, 1996) refers to the function of language to point to some object or association in the immediate situation. Lexicality, as defined by Srikant \& Roberts, 2004) refers to aspects of social identity the activity speakers are engaged in and their particular stance or perspective as well as more obvious pointers to time and space in the interaction. For example, in English 'now' not only refers to a time dimension but also may indicate affect used as an 
intensifier in utterances such as 'Now look what you've done!' The ability to interpret the lexicality of speech is therefore central to the conversational involvement of speakers and to their evaluation as competent performers in social life. It helps us understand how the process of language socialization is both a matter of interpreting and responding in the local production of talk and a matter of learning how to be and act in social contexts.

Stokes and Hewitt (1976) use the term "alignment" to encompass two meanings: (a) how individual conduct accords with that of co-participants in the creation of social acts; and (b) how problematic situations involve discrepancies between "what is actually taking place in a given situation and what is thought to be typical. These two meanings often converge, as alignments at the local, interactional level are primarily an index of the sociocultural norms of acceptability. Alignment, therefore, has a normative, moral dimension and where misalignments occur, there is a builtin justification for querying the suitability of a person's membership in a community.

\section{E. Social Theory of Learning}

Albert Bandura (1969) is the major motivator behind social learning theory, although the theory is inspired by Vygotsky's Socio-cultural theory and Lave's situated learning (i.e., learning is embedded in activity, context and culture) which also emphasize the importance of social learning. Bandura's Social Learning Theory posits that people learn from one another, via observation, imitation, and modeling. According to social learning theorists, learning can occur without a change in behavior. Behaviorists say that learning has to be represented by a permanent change in behavior, in contrast social learning theorists say that because people can learn through observation alone, their learning may not necessarily be shown in their performance. Learning may or may not result in a behavior. Bandura mentions four conditions that are necessary before an individual can successfully model the behavior of someone else:

- Attention: the person must first pay attention to the model.

Retention: the observer must be able to remember the behavior that has been observed. One way of increasing this is using the technique of rehearsal.

- Reproduction: the third condition is the ability to replicate the behavior that the model has just demonstrated. This means that the observer has to be able to replicate the action, which could be a problem with a learner who is not ready developmentally to replicate the action. For example, little children have difficulty doing complex physical motion.

- Motivation: the final necessary ingredient for modeling to occur is motivation, learners must want to demonstrate what they have learned. Remember that since these four conditions vary among individuals, different people will reproduce the same behavior differently.

Bandura believed in "reciprocal determinism", that is, the world and a person's behavior cause each other, while behaviorism essentially states that one's environment causes one's behavior. Later, Bandura soon considered personality as an interaction between three components: the environment, behavior, and one's psychological processes (one's ability to entertain images in minds and language).

\section{CONCLUSION}

Language development always takes place within a set of social contexts, ranging from the global linguistic order at one extreme to the classroom at the other. To many, the phrase "social context" may suggest no more than the societal setting in which events occur-home, school and so on. In recent years, however, a much more radical understanding of the importance of the social context of development has emerged as the result of a convergence of theoretical and empirical research in a variety of disciplines. According to this new understanding of social context, human beings are not only influenced by the social context in which they develop, but their very development as humans is dependent on opportunities to participate with others, notably parents, family members, peers and teachers, in the activities that constitute the culture in which they are growing up. Today the notion that human beings live their lives as solitary individuals is rejected. All of us live our lives in constant interaction with others. Understood in this way, the parts played by the significant others in our lives are undeniable.

Literature on the social context has suggested that we should capitalize on its natural interactional features for language development. But reality is far from ideality. The students for instance I work with in my country, for example, are not "free" to choose which languages they learn. Nor are they entirely free to decide their purposes in learning them. They are always subject to constraints ranging from those imposed by teachers and those imposed by policy makers, from micro constraints to macro ones. It seems the poor students are sentenced to adapt themselves to constraints.

While students are not free to ignore these constraints, they have one undeniable right: they are potentially free to criticize the existing context. However, discussion and criticism, of course, can also become empty if the people have no freedom to choose, decide and think. Consequently, this lends support to the claim that explicit attention to social contexts of learning and questioning of accepted purposes and goals will open a new horizon to a community that its context has a concept for those who live in it.

\section{REFERENCES}

[1] Bakhtin, M. M. (1981). The dialogic imagination. (C. Emerson \& M. Holquist, trans.). Austin: University of Texas Press.

[2] Bandura, A. (1969). Social-learning theory of identification processes. In D. A. Goslin (Ed.), Handbook of socialization theory and research (pp. 213-262). London: Rand McNally \& Company. 
[3] Bluestone, K. (2009). Acculturation, interpersonal networks, and the learner's sense of self: the effects of social relationships on second-language learning. Working Papers in TESOL and Applied Linguistics, 9 (2), 135-164.

[4] Duff, P. A., \& Talmy, S. (2011). Language socialization acquisition to second language acquisition. In D. Atkinson (Ed.), Alternative approaches to SLA (95-116). New York: Routledge.

[5] Ellis, R. (1990). The study of second language acquisition. Oxford: Oxford University Press.

[6] Firth, A., \& Wagner, J. (1997). On discourse, communication, and (some) fundamental concepts in SLA research. Modern Language Journal, 81, 285-300.

[7] Firth, A., \& Wagner, J. (2007). Second/foreign language learning as a social accomplishment: Elaborations on a reconceptualized SLA. The Modern Language Journal, 90, 800-819.

[8] Hymes, D, (1972). Reinventing anthropology. New York: Random House.

[9] Kesbir, S., Huttal, D. H., \& Gardner, W. (2010). Socialization: Insights from social cognition. Social and Personality Compass, $4(2), 93-106$

[10] Long, M. (1997). Construct validity in SLA research: A response to Firth and Wagner. Modern Language Journal, 81, 318-323

[11] Maccoby, E. (2007). Historical overview of socialization and theory. In J. E. Grusec \& P. D. Hastings, Handbook of socialization: Theory and practice (pp. 13-41). London: The Guilford Press.

[12] Mitchell, R., \& Myles, F. (2004). Second language learning theories ( $2^{\text {nd }}$ ed.). London: Hodder Arnold.

[13] Ochs, E. (1996) Linguistic resources for socialising humanity. In J.Gumperz \& S. Levinson (Eds), Rethinking Linguistic Relativity (pp. 407-437). Cambridge: Cambridge University Press.

[14] Seigel, J. (2003). Social context. In C. J. Doughty \& M. H. Long, The handbook of second language acquisition (pp. 178-223). Oxford: Blackwell Publishing.

[15] Spolksy, B. (1988). Bridging the gap: A general theory of second language learning. TESOL Quarterly, 22, 377-396.

[16] Stokes, R., \& Hewitt, J.P. (1976) Aligning actions. American Sociological Review 41, 838-49.

[17] Srikant, S., \& Roberts, C. (2004). Discoursal (mis)alignments in professional gatekeeping encounters. In C. Kramsch (Ed.), Language acquisition and language (pp. 197-227). London: Continuum.

[18] Sullivan, P. N. (2000). Playfulness as mediation in communicative language teaching in a Vietnamese classroom. In J. P. Lantolf, Sociocultural theory and second language learning (pp. 115-131). Oxford: Oxford University Press.

[19] Van Lier, L. (1996). Interaction in the language curriculum: awareness, autonomy, and authenticity. London: Longman.

[20] Van Dijk, T. (2006). Discourse and manipulation. Discourse and Society, 4, 249-283.

[21] Vygotsky, L. S. (1979). Consciousness as a problem in the psychology of behavior. Soviet Psychology, 17, 3-35.

[22] Watson-Gegeo, K. A., \& Nielsen, S. (2003). Language socialization in SLA. In C. J. Doughty \& M. H. Long, The handbook of second language acquisition (pp. 155-177). Oxford: Blackwell Publishing

[23] Wendt, M. (2003). Context, culture and construction: Research implications of theory formation in foreign language. In M. Byram \& P. Grundy (Eds.). Context and culture in language teaching and learning (pp. 92-119). Clevedon: Multilingual Matters.

[24] Wenger, E. (1998). Communities of practice: Learning, meaning and identity. New York: Cambridge University Press.

[25] Wilkins, D. (1974). Notional syllabuses and the concept of a minimum adequate grammar. In S. P. Corder, \& E. Roulet (Eds.). Linguistic Insights in Applied Linguistics. AIMAV/Didier.

[26] Zungler, J., \& Miller, E. R. (2006). Cognitive and sociocultural perspectives: two parallel SLA worlds. TESOL, 40 (1), $35-58$.

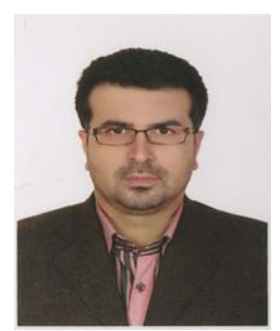

Nima Shakouri Masouleh is currently a Ph.D. candidate of TEFL at Azad University, Science and Research, Tehran, Iran. He is also a faculty member of Islamic Azad University, in Guilan. He has taught English courses for over a decade at different universities in Guilan. Moreover, he has published some articles in international journals and more than 7 English textbooks for GE and ESP courses.

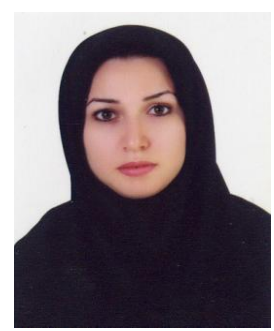

Razieh Bahraminezhad Jooneghani is currently a Master candidate of TESOL at Universiti Sains Malaysia (USM). She has the experience of teaching English in schools for over Five years. Furthermore, she has published one English book which is currently taught in some universities. 